\title{
IMPLEMENTATION OF CTL MODELS WITH PLASTISIN MEDIA TOWARDS COGNITIVE MAPPING OF STUDENTS IN BASIC SCHOOL LEARNING
}

\section{Siwi Utaminingtyas}

IKIP PGRI Wates

siwiutami66@gmail.com

\section{Article History}

accepted 30/09/2018

approved 12/10/2018

published 30/10/2018

Keywords

CTL Learning Model, cognitive mapping,

plasticine media

\begin{abstract}
Contextual learning (CTL) is a learning concept where the teacher presents the real world into the classroom and encourages students to make a connection between their knowledge and application in their daily lives, as a means to solve problems in everyday life. Learning with the CTL model opens the widest opportunity for students to empower themselves. Primary school children are the world of play, in the lives of children, most of their time is spent playing. Playing in learning provides an opportunity for children to express their creativity to find the use of things differently, find new relationships with one another. The use of plasticine as an IPS learning media can foster students' creativity in their learning, the game is more directed towards finding concept maps and interpreting the topic of existing learning material so as to foster learning motivation in achieving achievement.
\end{abstract}

Social, Humanities, and Education Studies (SHEs): Conference Series https://jurnal.uns.ac.id/shes 


\section{PENDAHULUAN}

Pendidikan merupakan suatu hal yang sangat penting bagi manusia dalam menghadapi kehidupan bermasyarakat, berbangsa, dan bernegara. Pendidikan menjadi modal dasar untuk mempersiapkan diri dalam menghadapi perkembangan yang pesat. Sejalan dengan kemajuan ilmu pengetahuan dan teknologi dalam era globalisasi ini, pemerintah terus melakukan berbagai macam kebijakan dalam meningkatkan mutu dan kualitas pendidikan. Proses pembelajaran dimantabkan agar materi pembelajaran dan diterima dengan mudah oleh peserta didik.

Di setiap jenjang pendidikan, seorang guru senantiasa mengharapkan agar peserta didik dapat mencapai prestasi belajar yang sebaik-baiknya. Dalam kenyataanya banyak peserta didik menunjukkan prestasi belajar yang tidak sesuai harapan. Beberapa peserta didik masih menunjukkan nilai-nilai yang rendah, masih ada peserta didik yang tidak dapat mengikuti pembelajaran dengan lancar atau dengan kata lain guru sering menghadapi peserta didik yang mengalami kesulitan belajar.

Rendahnya nilai-nilai peserta didik, terjadinya kesulitan belajar, bukan sematamata hanya kesalahan peserta didik tetapi dapat juga karena penggunaan model pembelajaran yang kurang tepat dan kurang diperhatikan selama pembelajaran berlangsung. Beberapa guru di lapangan masih ditemukan menggunakan model pembelajaran atau metode pembelajaran yang konvensional, tentunya berpusat pada guru belum berpusat pada peserta didik. Beberapa guru masih mengalami kesulitan bagaimana merancang model pembelajaran yang mudah dipahami peserta didik dan melibatkan peserta didik dalam proses pembelajaran.

Salah satu model pembelajaran yang mendukung pemahaman konsep IPS peserta didik adalah pembelajaran dengan menggunakan model Contextual Teaching Learning (CTL). Dengan CTL peserta didik dibimbing dan diarahkan dalam menemukan sendiri konsep materi pembelajaran. Pembelajaran dengan model CTL akan memungkinkan proses belajar yang tenang dan menyenangkan karena proses belajar dilakukan secara alamiah dan siswa dapat mempraktekkan secara langsung berbagai materi yang telah dipelajarinya serta mendorong siswa memahami hakikat, makna dan manfaat belajar sehingga akan memberikan stimulus dan motivasi kepada mereka untuk rajin belajar. Dengan demikian pembelajaran kontekstual (Contextual Teaching and Learning (CTL) diharapkan dapat memberikan pengetahuan konsep belajar yang membantu guru mengaitkan antara materi yang diajarkannya dengan situasi dunia nyata siswa dan mendorong siswa membuat hubungan antara pengetahuan yang dimilikinya dengan penerapannya dalam kehidupan mereka sebagai anggota keluarga dan masyarakat.

Peta konsep dapat berperan sebagai media pengajaran yang baik dan menarik karena peta konsep dapat menyederhanakan materi pelajaran yang kompleks sehingga memudahkan peserta didik dalam menerima dan memahami pembelajaran. Pembelajaran dengan menggunakan peta konsep mempunyai banyak manfaat, diantaranya pembelajaran jauh lebih bermakna dan berkesan, dengan mengacu pada peta konsep maka guru guru dapat membuat suatu program pengajaran yang lebih terarah, sehingga dalam pelaksanaan proses belajar mengajar dapat meningkatkan daya serap peserta didik terhadap materi yang diajarkan.

Peta konsep tidak dapat dilepaskan dari kreativitas peserta didik. Menurut Nursisto (1999: 6), kemampuan belajar peserta didik jadi lebih baik jika kemampuan kreativitasnya juga ikut dilibatkan. Berkembangnya kemampuan peserta didik untuk menggali kreativitas akan menjadi anak yang percaya diri dan mengurangi rasa takut salah. Apabila sudah timbul rasa percaya diri maka peserta didik akan jauh lebih optimis, dengan begitu peserta didik lebih semangat mengikuti pembelajaran di kelas. Salah satu media pembelajaran yang mendukung peningkatan kreativitas peserta didik adalah dengan media plastisin. Pengetahuan bukan hanya peniruan dari lingkungan peserta didik melainkan kepada konstruksi pemikiran. Piaget (Sujiono, 2008 : 56) 
menyatakan bahwa dengan media plastisin, anak dapat belajar meremas, menggilik, membangun konsep (cognitive mapping) tentang tugas yang dibuat.

\section{HASIL DAN PEMBAHASAN \\ Pengertian Contextual Teaching and Learning (CTL)}

Kata contextual berasal dari kata contex, yang berarti "hubungan, konteks, suasana, atau keadaan". Dengan demikian, contextual diartikan" yang berhubungan dengan suasana (konteks)". Sehingga, contextual teaching and learning (CTL) dapat diartikan sebagai suatu pembelajaran yang berhubungan dengan suasana tertentu.

Definisi mendasar tentang pembelajaran kontekstual (contextual teaching and learning) adalah konsep belajar dimana guru menghadirkan dunia nyata kedalam kelas dan mendorong siswa membuat hubungan antara pengetahuan yang dimilikinya dan penerapannya dalam kehidupan mereka sehari-hari, sementara siswa memperoleh pengetahuan dan keterampilannya dari konteks yang terbatas, sedikit demi sedikit, dan dari proses mengkontruksi sendiri, sebagai bekal untuk memecahkan masalah dalam kehidupannya sebagai anggota masyarakat.

Nurhadi (Hosnan, 2016: 267) mengemukakan CTL merupakan konsep belajar yang membantu guru dalam mengaitkan antara materi yang dipelajarinya dengan situasi dunia nyata siswa dan mendorong siswa membuat hubungan antara pengetahuan yang dimilikinya dengan penerapannya dalam kehidupan sehari-hari dengan melibatkan tujuh komponen pembelajaran efektif. Sedangkan Lailatul Istiqomah (Hosnan, 2016: 267) menyatakan pembelajaran kontekstual merupakan konsep belajar yang membantu guru mengaitkan antara materi pembelajaran dengan situasi dunia nyata dengan siswa, dan mendorong siswa membuat hubungan antara pengetahuan yang dimilikinya dengan penerapannya dalam kehidupan sehari-hari.

\section{Elemen dan Karakter CTL}

Menurut Zahorik (Hosnan, 2016: 269), terdapat lima elemen yang harus diperhatikan dalam praktek pembelajaran kontekstual .

a. Pengaktifan pengetahuan yang sudah ada (activiting knowledge).

b. Pemeroleh pengetahuan baru (acquiring knowledge) dengan cara mempelajari secara keseluruhan dulu, kemudian memperhatikan detailnya.

c. Pemahaman pengetahuan (understanding knowledge), yaitu dengan cara menyusun konsep-konsep sementara (hipotesis), melakukan sharing kepada orang lain agar mendapat tanggapan (validasi) dan atas dasar tanggapan itu konsep tersbut direvisi dan dikembangkan.

d. Mempraktikkan pengetahuan dan pengalaman tersebut (applying knowledge).

e. Melakukan refleksi (reflecting knowledge) terhadap strategi pengembangan pengetahuan tersebut.

Trianto (Hosnan, 2016: 269) mengemukakan selain elemen pokok, CTL juga memiliki karakteristik yang membedakan dengan model pembelajaran lainnya.
a. Kerja sama.
b. Saling menunjang.
c. Menyenangkan dan mengasyikkan.
d. Tidak membosankan (joyfull, comfortable).
e. Belajar dengan bergairah.
f. Pembelajaran terintegrasi.
g. Menggunakan berbagai sumber siswa aktif.

\section{Penerapan Pendekatan Kontekstual di Kelas}

Pembelajaran konstektual dengan pendekatan konstruktivisme dipandang sebagai salah satu strategi yang memenuhi prinsip pembelajaran berbasis kompetensi. Dengan lima strategi CTL, yaitu relating, experiencing, applying, cooperating, dan transferring, diharapkan siswa mampu mencapai kompetensi secara maksimal.

Tujuh komponen utama pembelajaran kontekstual, yakni kontruktivisme (contructivism), bertanya (questioning), inquiry, masyarakat belajar (community 
learning), pemodelan (modelling), dan penilaian autentik (authentic assessment). Berikut ini penjabaran ketujuh komponen tersebut.

1. Konstruktivisme (Constructivism)

Sanjaya (Hosnan, 2016: 270) mengemukakan kontruktivisme adalah proses membangun atau menyusun pengetahuan baru dalam struktur kognitif siswa berdasarkan pengalaman. Menurut konstruktivisme, pengetahuan itu memang berasal dari luar, tetapi dikonstruksi dari dalam diri seseorang.

Muslich (Hosnan, 2016: 270) mengemukakan, konstruktivisme adalah proses pembelajaran yang menekankan terbangunnya pemahaman sendiri secara aktif, kreatif dan produktif berdasarkan pengetahuan terdahulu dan dari pengalaman belajar yang bermakna. Pengetahuan bukanlah serangkaian fakta, konsep dan kaidah yang siap dipraktikannya. Manusia harus mengkonstruksikannya terlebih dahulu pengetahuan itu dan memberikan makna melalui pengalaman nyata.

2. Menemukan (Inquiry)

Komponen kedua dalam CTL adalah inquiry. Menurut Sanjaya (Hosnan, 2016: 270-271) inquiry, artinya proses pembelajaran didasarkan pada pencarian dan penemuan melalui proses berpikir secara sistematis. Secara umum proses, inquiry dapat dilakukan melalui beberapa langkah, yaitu merumuskan masalah, mengajukan hipotesa, mengumpulkan data, menguji hipotesis, dan membuat kesimpulan.

Muslich (Hosnan, 2016: 271) mengemukakan menemukan (inquiry) merupakan proses pembelajaran didasarkan pada pencarian dan penemuan. Kegiatan ini diawali dari pengamatan terhadap fenomena, dilanjutkan dengan kegiatan-kegiatan bermakna untuk menghasilkan temuan yang diperoleh sendiri oleh siswa. Pengetahuan dan keterampilan yang diperoleh siswa tidak dari hasil mengingat seperangkat fakta, tetapi hasil menemukan sendiri dari fakta yang dihadapinya.

3. Bertanya (Questioning)

Sanjaya (Hosnan, 2016: 271) mengemukakan belajar pada hakikatnya adalah bertanya dan menjawab pertanyaan. Bertanya dapat dipandang sebagai refleksi dari keingintahuan setiap individu, sedangkan menjawab pertanyaan mencerminkan kemampuan seseorang dalam berpikir.

Menurut Mulyasa (Hosnan, 2016: 271), ada 6 keterampilan bertanya dalam kegiatan pembelajaran, yakni pertanyaan yang jelas dan singkat, memberi acuan, memusatkan perhatian, memberi giliran dan menyebarkan pertanyaan, pemberin kesempatan berpikir, dan pemberian tuntunan. Dalam pembelajaran melalui CTL, guru tidak menyampaikan informasi begitu saja, tetapi memancing agar siswa dapat menemukan sendiri. Karena itu, peran bertanya sangat penting, sebab melalui pertanyaan-pertanyaan, guru dapat membimbing dan mengarahkan siswa untuk menemukan setiap materi yang dipelajarinya.

Trianto (Hosnan, 2016: 271-272) mengemukakan dalam sebuah pembelajaran yang produktif, kegiatan bertanya berguna untuk hal berikut ini.

a. Menggali informasi, baik administrasi, baik administrasi maupun akademis.

b. Mengecek pemahaman siswa.

c. Membangkitkan respons terhadap siswa.

d. Mengetahuai sejauh mana keingintahuan siswa.

e. Mengetahui hal-hal yang sudah diketahui siswa.

f. Memfokuskan perhatian siswa pada sesuatu yang dikehendaki guru.

g. Membangkitkan lebih banyak lagi pertanyaan dari siswa.

$\mathrm{h}$. Menyegarkan kembali pengetahuan siswa.

4. Masyarakat Belajar (Learning Community)

Sanjaya (Hosnan, 2016: 272) berpendapat berdasarkan pada pendapat Vygotsky, bahwa pengetahuan dan pemahaman anak banyak dibentuk oleh komunikasi dengan orang lain. Permasalahan tidak mungkin dipecahkan sendirian, tetapi membutuhkan orang lain. Konsep masyarakat belajar (learning community) 
dalam CTL adalah hasil pembelajaran diperoleh melalui kerjasama dengan orang lain, teman, antarkelompok, sumber lain dan bukan hanya guru.

Muslich (Hosnan, 2016: 272) mengemukakan konsep masyarakat belajar dalam CTL, menyarankan agar hasil pembelajaran diperoleh melalui kerjasama dengan orang lain. Hal ini berarti bahwa hasil belajar bisa diperoleh dangan sharing antarteman, antarkelompok, dan antar yang tahu kepada yang tidak tahu, baik didalam maupun diluar kelas.

5. Pemodelan (Modelling)

Sanjaya (Hosnan, 2016: 272) mengemukakan bahwa pemodelan adalah proses pembelajaran dengan memperagakan sesuatu sebagai contoh yang dapat ditiru oleh setiap siswa. Modeling merupakan azas yang sangat penting dalam pembelajaran CTL, sebab melalui modeling, siswa dapat terhindar dari pembelajaran yang teoretis (abstrak) yang dapat memungkinkan terjadinya verbalisme.

Menurut Muslich (Hosnan, 2016: 272) konsep pemodelan (modelling) dalam CTL menyarankan bahwa pembelajaran keterampilan dan pengetahuan tertentu diikuti dengan model yang bisa ditiru siswa. Model yang dimaksud bisa berupa pemberian contoh tentang cara mengoperasikan sesuatu, menunjukkan hasil karya atau mempertontonkan suatu penampilan. Cara pembelajaran seperti ini akan lebih cepat dipahami siswa dari pada hanya bercerita atau memberikan penjelasan kepada siswa tanpa ditunjukkan model atau contohnya. Dalam kegiatan pemodelan melalui contoh-contoh yang baik akan berguna sebagai contoh yang baik yang dapat ditiru oleh peserta didik, seperti cara menggali informasi, demonstrasi, dan lain-lain serta pemodelan dilakukan oleh guru (sebagai teladan), peserta didik, dan tokoh lain.

1. Refleksi (Reflektion)

Sanjaya (Hosnan, 2016: 272-273) berpendapat refleksi adalah proses pengendapan pengalaman yang telah dipelajari dengan cara mengurutkan kembali kejadian-kejadian atau peristiwa pembelajaran yang dilaluinya. Dalam proses pembelajaran dengan CTL, setiap berakhir proses pembelajaran, guru memberikan kesempatan kepada siswa untuk merenung atau mengingat kembali apa yang telah dipelajarinya.

Trianto (Hosnan, 2016: 273) berpendapat refleksi adalah cara berpikir tentang apa yang baru dipelajari atau berpikir kebelakang rentang apa-apa yang sudah kita lakukan di masa yang lalu. Siswa mengendapkan apa yang baru dipelajarinya sebagai struktur penetahuan yang baru, yang merupakan pengayaan atau revisi dari pengetahuan sebelumnya. Refleksi merupakan respons terhadap kejadian, aktivitas, atau pengetahuan yang baru diterima.

Pada akhir pembelajaran, guru menyisakan waktu sejenak agar siswa melakukan refleksi. Realisasinya berupa berikut ini.

a. Pernyataan langsung tentang apa-apa yang diperolehnya hari itu.

b. Catatan atau jurnal di buku siswa.

c. Kesan dan saran siswa mengenai pembelajaran hari itu.

d. Diskusi.

e. Hasil karya.

2. Penilaian Nyata (Authentic Assessment)

a. Menilai sikap, pengetahuan, dan keterampilan.

b. Berlangsung selama proses secara terintegrasi.

c. Dilakukan melalui berbagai cara (tes dan nontes).

d. Alternatif bentuk kinerja, observasi, portofolio, dan atau jurnal.

\section{Cognitive Mapping (Peta Konsep)}

Carrol (Kadir, 1997: 2) menyatakan bahwa konsep merupakan suatu abstraksi dari serangkaian pengalaman yang didefinisikan sebagai suatu kelompok objek atau kejadian. Bobbi De Porter (2007: 175) menyatakan bahwa peta konsep merupakan metode pencatatan 
yang baik, membantu peserta didik mengingat perkataan atau bacaan, meningkatkan pemahaman terhadap materi, membantu mengorganisasikan materi dan memberikan wawasan baru.

Peta konsep lebih memberdayakan pada proses berpikir analisis dan logika, peserta didik berpikir analisis dan logika dari pembuatan peta konsep yang dibuat oleh peserta didik. Peserta didik dapat belajar lebih efektif dan bermakna, selain itu peta konsep dalam proses belajar mengajar di kelas dapat mengurangi kepasifan peserta didik.

Dengan mengacu pada peta konsep maka guru dapat membuat suatu program pengajaran yang lebih terarah dan berjenjang, sehingga pelaksanaan proses belajar mengajar dapat meningkatkan daya serap peserta didik terhadap materi yang diajarkan. Jadi, peta konsep merupakan alat sekaligus cara yang dapat digunakan dalam proses pembelajaran, menghubungkan antara konsep satu dengan konsep yang lainnya, sehingga apa yang dipelajari peserta didik menjadi lebih bermakna, lebih mudah diingat dan lebih mudah dipahami untuk mengungkapkan kembali apa saja yang diperoleh oleh peserta didik setelah proses pembelajaran

\section{Jenis-Jenis Concept Mapping (Peta Konsep)}

Nur (2000: 15) menyatakan bahwa jenis-jenis peta konsep ada 4 macam, yaitu "pohon jaringan (network tree), rantai kejadian (event chain), peta konsep siklus (cycle concept map), dan peta konsep laba-laba (spider concept map).

1. Pohon Jaringan (network tree)

Ide-ide pokok dibuat dalam persegi empat, sedangkan beberapa kata lainnya dihubungkan, kata pada garis penghubung memberikan hubungan antara konsep-konsep. Pohon jaringan cocok untuk memvisualisasikan hal-hal seperti menunjukkan informasi sebab akibat, suatu hirarki.

2. Rantai Kejadian (event chain)

Peta konsep rantai kejadian dapat digunakan untuk memberikan suatu urutan kejadian, langkah-langkah suatu prosedur, atau tahapan suatu proses.

3. Peta Konsep Siklus (cycle concept map)

Dalam peta konsep siklus, rangkaian kejadian tidak menghasilkan suatu hasil akhir. Kejadian akhir pada rantai itu menghubungkan kembali kejadian awal, dan seterusnya.

4. Peta Konsep Laba-Laba (spider concept map)

Peta konsep laba-laba digunakan untuk curah pendapat. Dalam melakukan curah pendapat ide-ide berasal dari suatu ide sentral, sehingga banyak ide-ide tersebut belum tentu berkaitan dengan ide sentral. 
Penerapan model CTL dengan media plastisin dalam Pembelajaran IPS 1. Benua Australia - IPS kelas 6

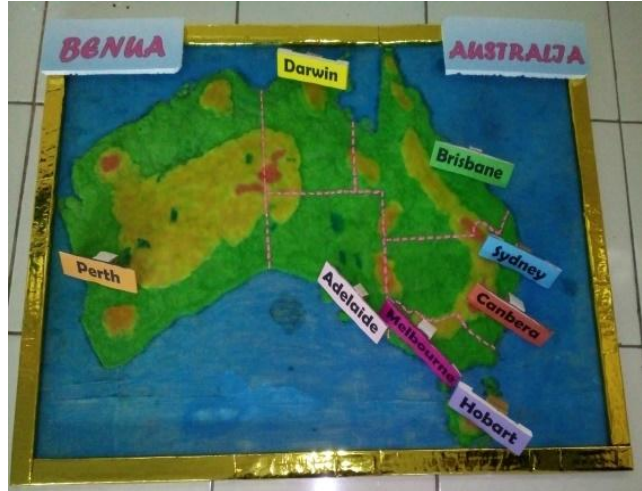

Gambar 1. Peta Benua Australia

2. Perairan Indonesia - Kelas 5

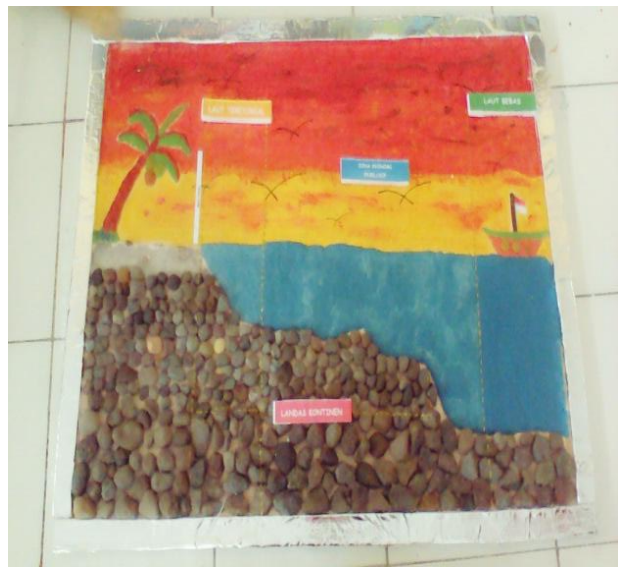

Gambar 2. Perairan Indonesia

3. Benua Asia Tenggara - kelas 6

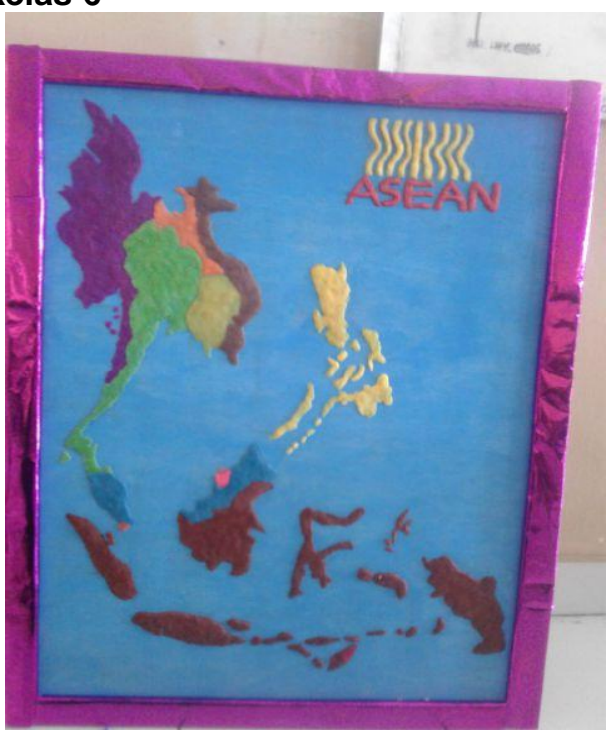

Gambar 3. Peta Benua Asia Tenggara 


\section{SIMPULAN}

Pembelajaran kontekstual dapat dikatakan sebagai sebuah model pembelajaran yang mengakui dan menunjukkan kondisi alamiah dari pegetahuan. Melalui hubungan di dalam dan di luar ruang kelas, suatu pembelajaran dengan model kontekstual menjadikan pengalaman lebih relevan dan bermakna bagi siswa dalam membangun pengetahuan yang akan mereka terapkan dalam kehidupan sehari-hari. Pembelajaran kontekstual menyajikan suatu konsep yang mengaitkan materi pelajaran yang dipelajari siswa dengan konteks dimana materi ajar digunakan. Pembelajaran dengan model CTL melalui penggunaan plastisin dapat mendorong siswa lebih aktif, kreatif, membangun peta konsep pada materi pembelajaran, membangun kerjasama dengan kegiatan kelompok, saling menunjang, belajar dengan gairah dan guru kreatif serta memudahkan guru dalam proses pembelajaran.

Sesuai dengan krakterisitik CTL, pembelajaran dapat memberikan kesempatan kepada siswa untuk mengetahui hal-hal yang memiliki makna, dilakukan melalui kegiatan berkelompok, memberikan kesempatan untuk bekerja sama dan dilakukan secara aktif, kreatif, produktif dan kerjasama, sehingga dengan menggunakan permainan dalam kegitan belajar mengajar dapat menciptakan suasana belajar yang produktif, keratif dan membangun kebersamaan antar siswa.

\section{DAFTAR PUSTAKA}

DePorter, Bobbi, dkk. 2007). Quantum Teaching: Mempraktikkan Quantum Learning di Ruangruang Kelas. Bandung: PT Mizan Pustaka.

Hosnan, M. (2016). Pendekatan Saintifik dan Kontekstual dalam Pembelajaran Abad 21: Kunci Sukses Implementasi Kurikulum 2013. Bogor: Ghalia Indonesia.

Kadir. (1997). Efektifitas Strategi Peta Konsep dalam Pembelajaran Sains dan Matematika. Jakarta :

Nursito. (1999). Kiat Menggali Kreativitas. Yogyakarta: Mitra Gama Widya.

Nur, Mohammad. (2000). Strategi-stretegi Belajar. Surabaya: UNESA-University Press.

Sujiono, Yuliani Nurani. (2008). Metode Pengembangan Kognitif. Jakarta : Universitas Terbuka 